\title{
Quasi-solid state synthesis of EU-1 zeolite and its catalytic properties for the isomerization of $\mathrm{C}_{8}$ aromatics
}

\author{
Gui Peng ${ }^{1}$, Li Xiaofeng ${ }^{1 * *}, Z_{\text {Zhang Shang }}^{2}$, Xu Qinghu ${ }^{3,4}$ and Dou Tao ${ }^{1,4 *}$ \\ ${ }^{1}$ Chemical Engineering Department, Taiyuan University of Technology, Taiyuan, Shanxi 030024, China \\ ${ }^{2}$ Petrochemical Research Institute, CNPC, Beijing 100083, China \\ ${ }^{3}$ New Energy Research Institute, CNOOC New Energy Investment Co., Ltd., Beijing 100016, China \\ ${ }^{4}$ China University of Petroleum, Beijing102249, China
}

(C) China University of Petroleum (Beijing) and Springer-Verlag Berlin Heidelberg 2012

\begin{abstract}
In this study, EU-1 zeolite was successfully synthesized via a quasi-solid state approach and assembled to catalyst for the $\mathrm{C}_{8}$ aromatics isomerization process. The catalytic properties were tuned through careful modification of the acidity of EU-1 zeolites and metal-doping of the catalyst. It was shown that EU-1 was an excellent candidate for the $\mathrm{C}_{8}$ aromatics isomerization process due to its unique structure. In addition, steam treatment of EU-1 at $450-500{ }^{\circ} \mathrm{C}$ could optimize the acidic properties of the catalyst, hence enhance its catalytic performance. The effect of the amount of Pt on ethylbenzene conversion was studied and the optimum amount was determined to be about $0.3-0.4 \mathrm{wt} \%$. It was confirmed that EU-1 zeolite prepared via a quasi-solid state approach and then dealuminated by steam treatment had better activity and selectivity than conventional mordenite (MOR) zeolite and could be an excellent candidate for $\mathrm{C}_{8}$ aromatics isomerization.
\end{abstract}

Key words: EU-1 zeolite, acidity, metallic function, isomerization

\section{Introduction}

$\mathrm{C}_{8}$ aromatics is the mixture of four isomers, namely p-xylene (PX), m-xylene (MX), o-xylene (OX) and ethylbenzene (EB), which are all very important basic chemicals in industry (Gao, 1999). Among the four isomers, the demand for PX is increasing with the rapid development of chemical fibers (Mi, 2008). At present, $\mathrm{C}_{8}$ aromatics cannot meet the demand and the limited $\mathrm{C}_{8}$ feedstock should be used more efficiently. Therefore, development of catalysts for the $\mathrm{C}_{8}$ isomerization process is an important issue.

The convention of EB to PX could be a solution for the aforementioned questions (Wang et al, 2004). So far, there are several catalysts available for use, such as I-400 developed by the Universal Oil Products (UOP) Company, USA, Oparis by Institut Français du Pétrole (IFP), France, and SKI-400 by Research Institute of Petroleum Processing (RIPP) of Sinopec, China (Moreau et al, 2006; Yang and Shi, 2005).

Among them, mordenite (MOR) zeolite is the most widely used acidic part of the catalyst for isomerization of EB to PX, but MOR zeolite is poor in activity and selectivity, due to its structural defects. Meanwhile, other new zeolites have

*Corresponding author. email: dtao1@163.com

**Corresponding author. email: lixiaofeng6008@163.com

Received March 13, 2012 been studied (Yeong et al, 2010; Tukur and Al-Khattaf, 2011) to enhance the catalytic performance in the $\mathrm{C}_{8}$ isomerization process.

EU-1 zeolite, with the EUO structure shown in Fig. 1 (Souverijns et al, 1995), has a 1-dimensional channel along the [100] direction with 10-membered rings (MR) $(0.58 \times 0.41 \mathrm{~nm})($ Briscoe et al, 1988; Souverijns et al, 1995), and there are two groups of these channels in each unit cell. In addition, the empty 12-membered ring side-pockets with a depth of about $0.81 \mathrm{~nm}$ connect the main channels beside the 10 -membered rings. The 12 -membered rings are connected by the 2-fold helix axis. Based on the structural features, Moreau et al (2006) have studied the EB isomerization on the EU-1 based catalyst with Pt as the metal functional component and proved that this acidic environment shows very good performance in the isomerization of EB to PX due to the unique side-pockets in the EU-1 structure.

Structurally, the side-pockets of the 12 -membered ring in EU-1 have dimensions of about $0.68 \times 0.58 \mathrm{~nm}$. Because the dynamic diameter of EB, PX, MX and OX are 0.57, 0.59, 0.68 and $0.68 \mathrm{~nm}$, respectively, only the EB molecule can enter the side-pockets of EU-1. Fig. 2 shows the mechanism of EB conversion (Gnep et al, 1980), which undergoes four steps. Side reactions can take place during the catalytic cracking process and these would lower the reaction selectivity. However, the side-pockets in EU-1 can accommodate the EB 


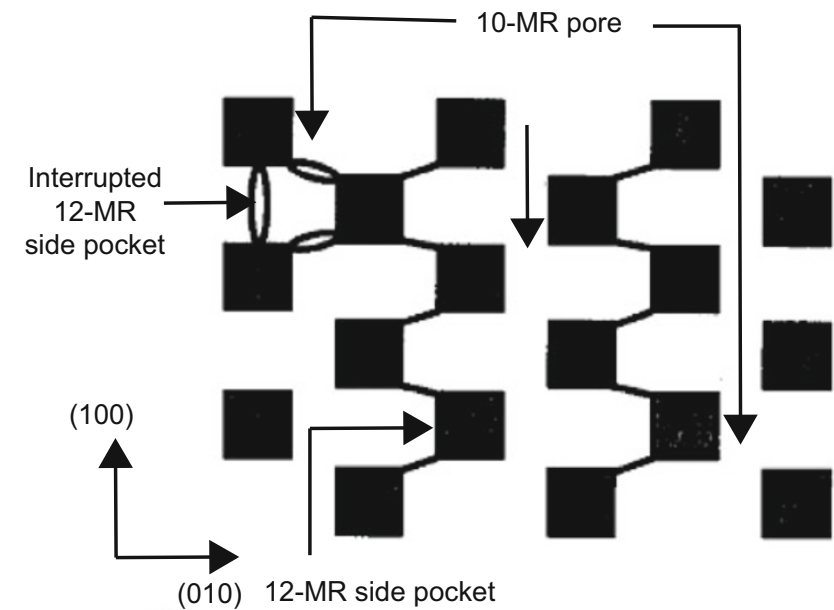

Fig. 1 Section through the EU-1 framework structure perpendicular to the (001) direction showing the 10-MR pore system with 12-MR side-pockets

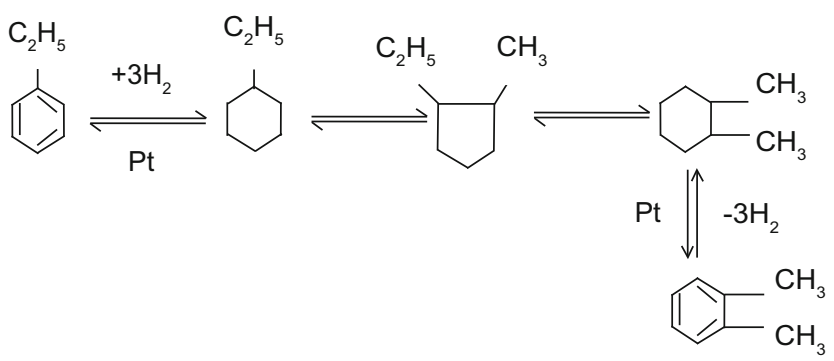

Fig. 2 The mechanism of EB conversion on Pt/zeolites catalyst

molecules, so a catalyst with EU-1 as acid sites will result in a change in reaction selectivity.

In addition, the strong acidity of EU-1 zeolite will result in cracking and disproportionation reactions.

Conventionally, EU-1 zeolite is prepared via hydrothermal synthesis (Casci et al, 1981) or the dry-gel conversion (Arnold et al, 2004; Goeergen et al, 2007). In our work team's previous research work (Dou et al, 2009; Xu et al, 2011), EU-1 zeolite has been prepared via a quasi-solid state reaction for the first time. Following that, catalysts based on an EU-1 parent were developed for isomerization reactions, and their industrial application in isomerization of $\mathrm{C}_{8}$ aromatics has been implemented in China, and reported as a new catalyst with high catalytic selectivity by Shi (2009).

In this paper, EU-1 zeolite was prepared by a quasi-solid state conversion and the textural properties were compared with those of EU-1 prepared by hydrothermal synthesis. The obtained EU-1 zeolite was then dealuminated by steam treatment to adjust the acidity. In addition, the matching between metal and acidic function was studied. The objective of all the works was to increase the selectivity to $\mathrm{C}_{8}$ aromatics while keeping high activity in the $\mathrm{C}_{8}$ isomerization processes.

\section{Experimental}

\subsection{Synthesis of EU-1 and post treatments}

Synthesis of EU-1 zeolite via quasi-solid state reaction: $\mathrm{NaOH}$ (99 wt\%, A.R.) was dissolved in water, then hexamethonium bromide $\left(\mathrm{HMBr}_{2},>98 \mathrm{wt} \%\right.$, A.R.) used as the structure directing agent (SDA) was added to the solution and stirred at about $50-60{ }^{\circ} \mathrm{C}$ till fully dissolved. This solution was cooled to room temperature and $\mathrm{SiO}_{2}-\mathrm{Al}_{2} \mathrm{O}_{3}$ microspheres $\left(n\left(\mathrm{SiO}_{2}\right) / n\left(\mathrm{Al}_{2} \mathrm{O}_{3}\right)=10.2, m\left(\mathrm{Na}_{2} \mathrm{O}\right)<0.2 \%\right)$ and silica gel $\left(\mathrm{SiO}_{2}, 98 \mathrm{wt} \%\right)$ were added. The molar ratio of the initial gel was $\mathrm{HMBr}_{2}: \mathrm{Na}_{2} \mathrm{O}: \mathrm{Al}_{2} \mathrm{O}_{3}: \mathrm{SiO}_{2}: \mathrm{H}_{2} \mathrm{O}=20: 11: 1: 55: 500$. Then, the gel was transferred into a Teflon-coated stainless steel autoclave and kept at $180{ }^{\circ} \mathrm{C}$ for $48 \mathrm{~h}$. Finally, the sample was washed, dried and denoted EU-1(S) (Dou et al, 2009).

Synthesis of EU-1 zeolite via hydrothermal reaction: EU-1 was prepared (Casci et al, 1981), the molar ratio of the raw chemicals was $\mathrm{HMBr}_{2}: \mathrm{Na}_{2} \mathrm{O}: \mathrm{Al}_{2} \mathrm{O}_{3}: \mathrm{SiO}_{2}: \mathrm{H}_{2} \mathrm{O}=$ $30: 30: 1: 55: 3000$. The other conditions are the same as the quasi-solid state approach. The sample was denoted EU-1(H).

Both the EU-1(S) and the EU-1(H) sample were ground and then heated in a muffle furnace at $550{ }^{\circ} \mathrm{C}$ for $6 \mathrm{~h}$ with a heating rate of $2{ }^{\circ} \mathrm{C} / \mathrm{min}$ to remove the SDA molecules.

Ion exchange was performed in $\mathrm{NH}_{4} \mathrm{NO}_{3}$ solution (1.0 $\mathrm{mol} / \mathrm{L}$ ) at $95{ }^{\circ} \mathrm{C}$ for $2 \mathrm{~h}$ to obtain H-type EU-1 zeolite. The mass ratio of EU-1 to exchange solution was 1:15. H-type EU-1 zeolite was then modified through steam treatment to adjust its acidity at temperatures of between $300{ }^{\circ} \mathrm{C}$ and 500 ${ }^{\circ} \mathrm{C}$, a liquid hourly space velocity (LHSV) of water of $1.0 \mathrm{~h}^{-1}$, and a processing time of 2 hours.

\subsection{Catalyst preparation}

Zeolite and aluminum hydroxide (AR) were mixed uniformly, and then $3 \mathrm{wt} \%$ nitric acidaqueous solution was added, and followed by the processes of kneading, extruding, drying, pelletizingand calcining to get the alumina carrier. After that, ion exchange was carried out between the zeolite and ammonium chloride (AR) (weight ratio, 1:0.35) in an $80-90{ }^{\circ} \mathrm{C}$ water bath for 2 hours, and then the carrier was washed carefully with pure water to remove all the $\mathrm{Cl}^{-}$. Then, the carrier was immersed in a mixture of chloroplatinicacid (AR) and competitive adsorbent trichloroacetic acid (AR, 3 wt $\%$ ) for 12 hours. Finally, themother liquor was removed and the remainder was treated by the processes of curing, activation and reduction to get the final catalyst.

\subsection{Characterization}

X-ray diffraction (XRD) patterns for crystalline structureand crystallinity identification were recorded on a X-ray powder diffractometer (Bruker D8 Advance diffractometer, Germany) with $\mathrm{Cu}-\mathrm{K} \alpha$ radiation $(\alpha=1.5418$ $\AA$ ). The XRD data were collected in a continuous scanning mode from $5-35^{\circ}(2 \theta)$ at a scanning rate of $4 \% \mathrm{~min}$. The bulk $\mathrm{SiO}_{2} / \mathrm{Al}_{2} \mathrm{O}_{3}$ ratios were determined by X-ray fluorescence (XRF) analysis using a Rigaku ZSX-100e X-ray fluorescence spectrometer (Rigaku Corporation, Japan).

The specific surface area of the samples was determined by using nitrogen adsorption-desorption isotherms recorded at $-196{ }^{\circ} \mathrm{C}$ on an ASAP2000 automatic physical adsorption analyzer (Micromeritics instrument Corp., USA). The total specific surface area was calculated by the BET (BrunauerEmmertt-Teller) formula, pore size distribution was calculated by the BJH (Barrett-Joyner-Halenda) model, and the micropore volume and micropore specific surface area 
were determined by using t-plot method.

The morphology of the EU-1 zeolite was observedwith a high resolution transmission electron microscopy (TEM, FEI Tecnai $\mathrm{G}^{2} \mathrm{~F} 20$ ).

The Brønsted and Lewis acid sites of the samples were investigated by using Fourier transform infrared spectroscopy of pyridine adsorption (Py-FTIR) in an in-situ cell. Selfsupporting wafers of the samples were pretreated at $350{ }^{\circ} \mathrm{C}$ for $2 \mathrm{~h}$ under $10^{-3} \mathrm{~Pa}$ and then cooled to $200{ }^{\circ} \mathrm{C}$. After pyridine adsorption at $30^{\circ} \mathrm{C}$ for $10 \mathrm{~min}$ and then evacuation at each of $200{ }^{\circ} \mathrm{C}$ and $350{ }^{\circ} \mathrm{C}$ for $30 \mathrm{~min}$, was performed respectively, the IR spectra were recorded on a Magna-IR 560 FT-IR instrument (NiCOLET Corp., USA). The Brønsted acidity was quantified using the integrated areas of the absorbance peaks at $1,540 \mathrm{~cm}^{-1}$. The total acidity and strong Brønsted acidity at $200{ }^{\circ} \mathrm{C}$ and $350{ }^{\circ} \mathrm{C}$ were obtained.

\subsection{Catalyst performance evaluation}

Fig. 3 shows the catalyst evaluation system. The catalyst loading capacity was $15.0 \mathrm{~g}$ and the purity of hydrogen for reaction was 99.99 vol\%. After the operation was stable, sample was collected from the product tank once every 8 hours.

The composition of the feedstocks, which was from

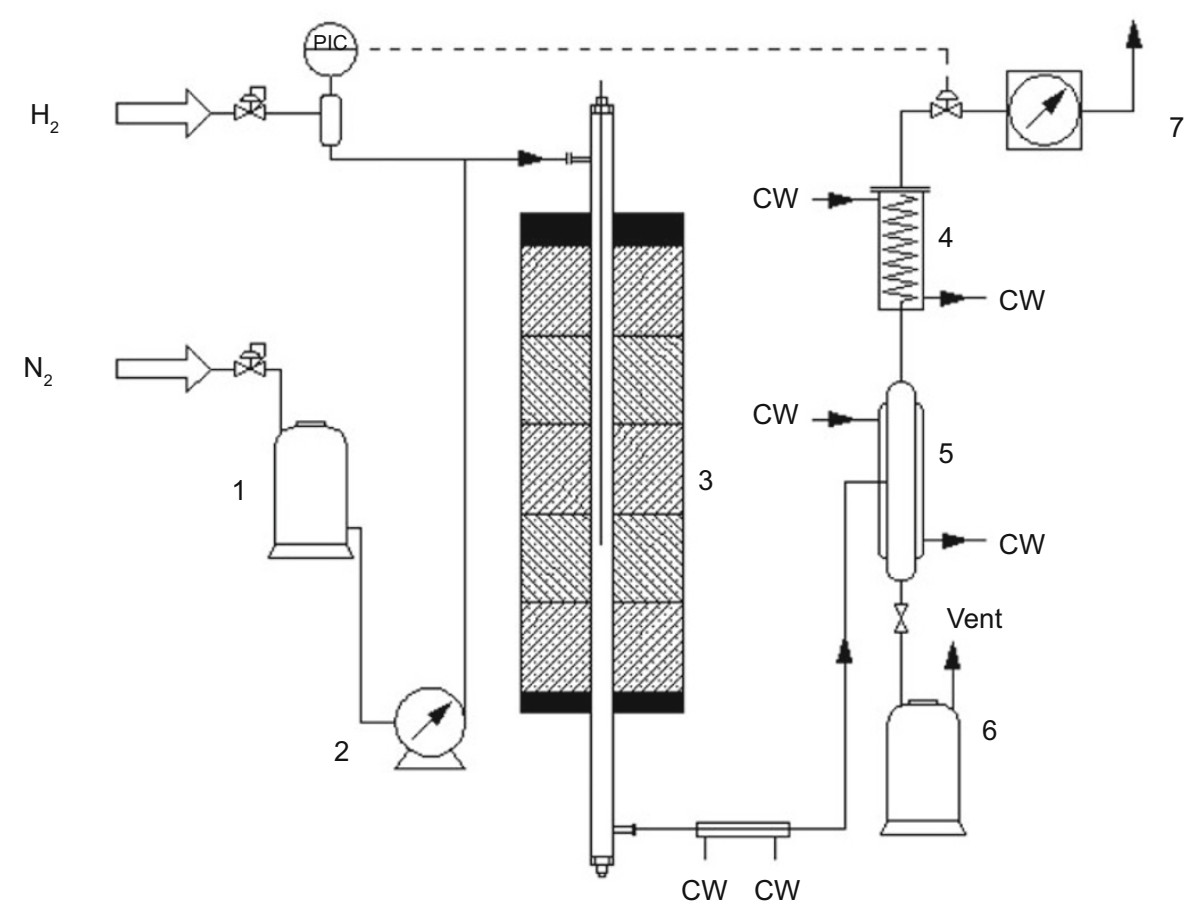

Fig. 3 Catalyst evaluation system

1-Feed tank; 2-Feed pump; 3-Reactor; 4-Heat exchanger; 5-High pressure separator; 6-Product tank; 7-Wet gas flow meter; CW-Cool water

industrial plant for catalyst performance evaluation, is listed in Table 1.

Table 1 Composition of the feedstock (wt\%)

\begin{tabular}{ccccccccc}
\hline $\mathrm{C}_{7}{ }^{\mathrm{N}+\mathrm{P}}$ & $\mathrm{C}_{8}^{\mathrm{N}+\mathrm{P}}$ & $\mathrm{B}$ & $\mathrm{T}$ & $\mathrm{EB}$ & $\mathrm{PX}$ & $\mathrm{MX}$ & $\mathrm{OX}$ & $\mathrm{C}_{9}{ }^{\mathrm{A}}$ \\
\hline 0.08 & 9.70 & 0 & 1.12 & 13.04 & 1.43 & 55.91 & 18.72 & 0 \\
\hline
\end{tabular}

Notes: $\mathrm{C}_{7}{ }^{\mathrm{N}+\mathrm{P}}: \mathrm{C}_{7}$ naphthenes and paraffins or lighter components; $\mathrm{C}_{8}{ }^{\mathrm{N}+\mathrm{P}}$ : $\mathrm{C}_{8}$ naphthenes and paraffins; $\mathrm{B}$ : benzene; $\mathrm{T}$ : toluene; $\mathrm{EB}$ : ethylbenzene; PX: p-xylene; MX: m-xylene; OX: o-xylene; $\mathrm{C}_{9}{ }^{\mathrm{A}}: \mathrm{C}_{9}$ or heavier aromatics.

The products were analyzed by gas chromatography using an Agilent 6820, and an Agilent Cerity QC-QA chromatography workstation (Agilent Corporation, USA) was used for processing data. In this study, the equilibrium concentration of $\mathrm{PX}(\mathrm{PX} / \Sigma \mathrm{X})$ and ethylbenzene conversion rate $\left(\mathrm{EB}_{\mathrm{C}}\right)$ was used as the activity index, while the yield of $\mathrm{C}_{8}$ was used as the selective index. The formulas for the three indexes are shown from Eq. (1) to Eq. (3).

$$
\begin{aligned}
& \mathrm{PX} / \sum \mathrm{X}=\frac{w(\mathrm{PX})_{\mathrm{P}}}{w(\mathrm{PX})_{\mathrm{P}}+w(\mathrm{MX})_{\mathrm{P}}+w(\mathrm{OX})_{\mathrm{P}}} \times 100 \% \\
& \mathrm{~EB}_{\mathrm{C}}=\frac{w(\mathrm{~EB})_{\mathrm{F}}-w(\mathrm{~EB})_{\mathrm{P}}}{w(\mathrm{~EB})_{\mathrm{F}}} \times 100 \% \\
& C_{8} Y=\frac{w(\mathrm{~EB})_{\mathrm{P}}+w(\mathrm{X})_{\mathrm{P}}+w\left(\mathrm{C}_{8}^{\mathrm{N}+\mathrm{P}}\right)_{\mathrm{P}}}{w(\mathrm{~EB})_{\mathrm{F}}+w(\mathrm{X})_{\mathrm{F}}+w\left(\mathrm{C}_{8}^{\mathrm{N}+\mathrm{P}}\right)_{\mathrm{F}}} \times 100 \%
\end{aligned}
$$

where,

$w(\mathrm{PX})_{\mathrm{P}}$ is the mass fraction of $\mathrm{PX}$ in the products, $\mathrm{wt} \%$; $w(\mathrm{MX})_{\mathrm{P}}$ is the mass fraction of $\mathrm{MX}$ in the products, $\mathrm{wt} \%$; $w(\mathrm{OX})_{\mathrm{P}}$ is the mass fraction of $\mathrm{OX}$ in the products, $\mathrm{wt} \%$; $w(\mathrm{~EB})_{\mathrm{P}}$ is the mass fraction of $\mathrm{EB}$ in the products, $\mathrm{wt} \%$; $w(\mathrm{~EB})_{\mathrm{F}}$ is the mass fraction of $\mathrm{EB}$ in the feedstock, $\mathrm{wt} \%$; $w(\mathrm{X})_{\mathrm{P}}$ is the mass fraction of xylene in the products, $\mathrm{wt} \%$; $w(\mathrm{X})_{\mathrm{F}}$ is the mass fraction of xylene in the feedstocks, $\mathrm{wt} \%$; $w\left(\mathrm{C}_{8}^{\mathrm{N}+\mathrm{P}}\right)_{\mathrm{P}}$ is the mass fraction of $\mathrm{C}_{8}^{\mathrm{N}+\mathrm{P}}$ in the products, $\mathrm{wt} \%$; $w\left(\mathrm{C}_{8}^{\mathrm{N}+\mathrm{P}}\right)_{\mathrm{F}}$ is the mass fraction of $\mathrm{C}_{8}^{\mathrm{N}+\mathrm{P}}$ in the feedstocks, $\mathrm{wt} \%$. 


\section{Results and discussion}

\subsection{Textural properties of EU-1 zeolite}

In this study, a special synthesis route (the quasi-solid state approach) was designed to prepare the EU-1 zeolite with characteristic structure, and the chemical nature of the catalytic reaction was investigated in view of the unique structure of the zeolite.

Fig. 4 shows the XRD patterns of the EU- 1 zeolites prepared by the quasi-solid state approach (denoted EU$1(\mathrm{~S})$ ) and via conventional hydrothermal process (denoted EU-1(H)). It is shown that EU-1 zeolite was successfully prepared by the quasi-solid state conversion. In addition, their diffraction intensities have almost no difference, indicating that the EU-1 zeolite prepared via the both different approaches has no difference in crystallinity.

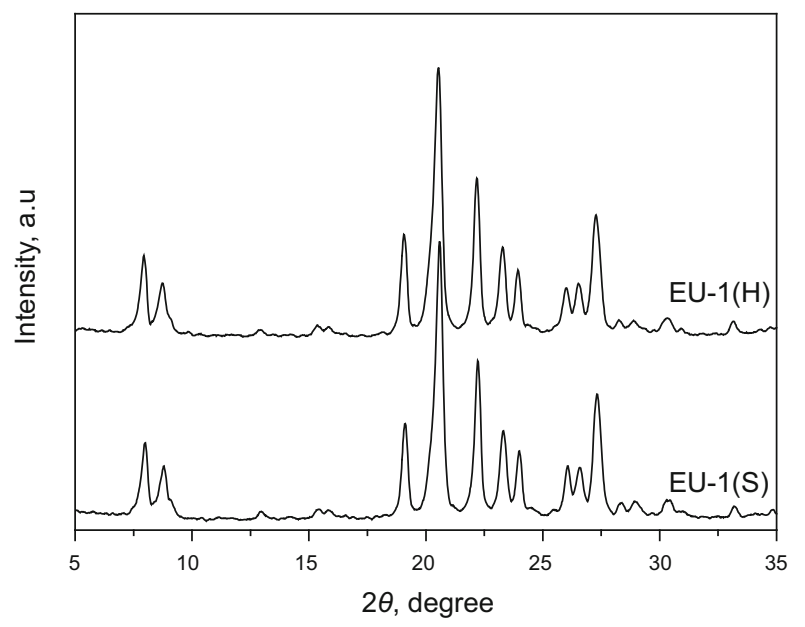

Fig. 4 XRD patterns of EU-1 zeolites

Fig. 5 shows the isotherms and pore size distribution of EU-1 zeolites synthesized by two different approaches. The isotherms of both EU-1(S) and EU-1(H) showed type IV behavior. Meanwhile, compared with the EU-1(H) sample synthesized by the hydrothermal method, the isotherms of the EU-1(S) sample synthesized by the quasi-solid state method had a larger hysteresis loop at a relative pressure of 0.5-0.9, indicating the presence of mesopores and a mesoporous size distribution. From the results of pore size distribution, it can be seen that EU-1(S) had pore size distribution in 3-30 nm, while the same result was not found for the EU-1(H) zeolite. The reason might be that the mesopores of the raw materials (silica gel and silica-alumina microsphere) are preserved in the quasi-solid state approach.

Table 2 lists the data of the surface area and pore volume of EU-1 zeolite. The BET surface area was almost the same for the both EU-1 samples, while the external area of EU-1(S) was $37 \mathrm{~m}^{2} / \mathrm{g}$, higher than that of EU-1(H) by $13 \mathrm{~m}^{2} / \mathrm{g}$. The total pore volume of EU-1(S) was $0.243 \mathrm{~cm}^{3} / \mathrm{g}$, which is also higher than that of EU-1(H). Moreover, the mesopore volume of EU-1(S) was $0.095 \mathrm{~cm}^{3} / \mathrm{g}$, much higher than that of EU$1(\mathrm{H})\left(0.065 \mathrm{~cm}^{3} / \mathrm{g}\right)$. The results indicated that EU-1(S) had more mesopore structure.
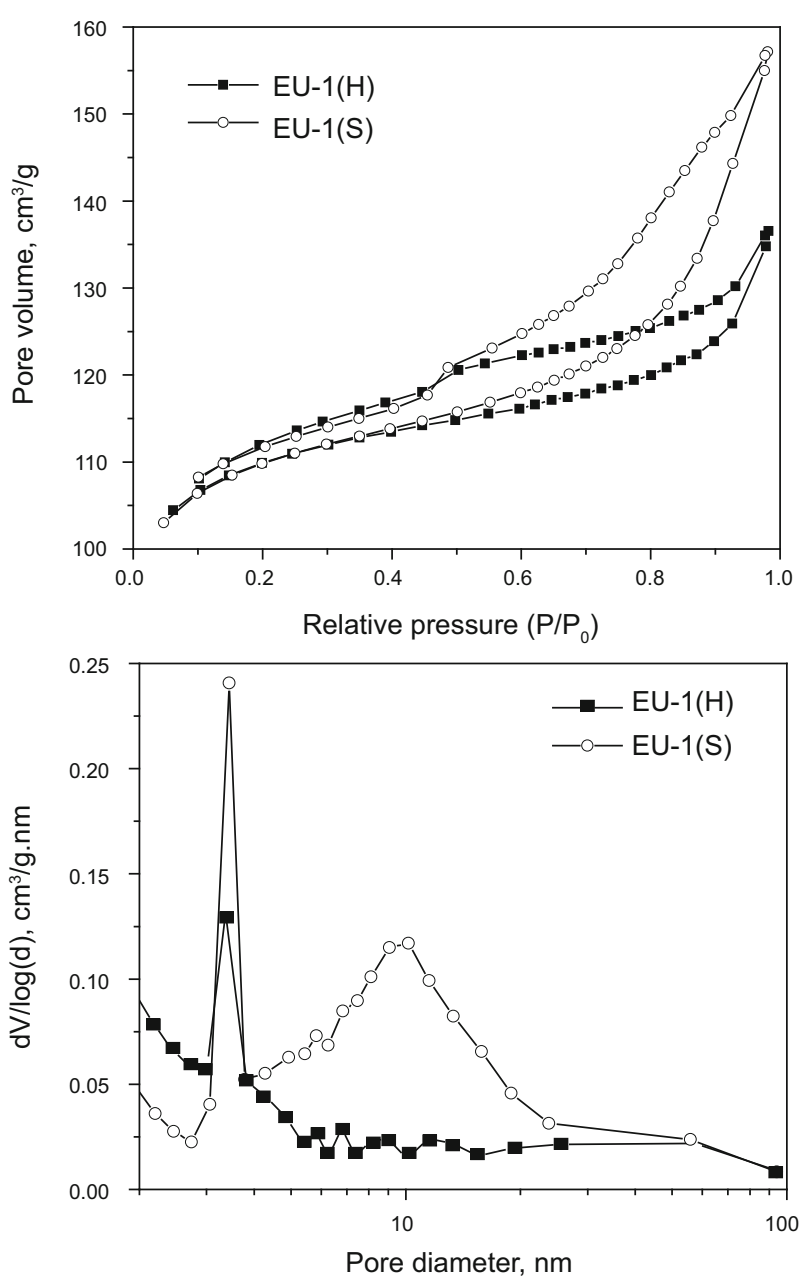

Fig. $5 \mathrm{~N}_{2}$ adsorption/desorption isotherms and pore diameter distribution of EU-1 zeolites

The TEM micrograph (Fig. 6) shows that the EU-1(S) sample was nanoclusters formed of microcrystals with a crystallite size mostly between 10 and $20 \mathrm{~nm}$. A broad pore size distribution $(3-30 \mathrm{~nm})$ was formed from the nanoclusters. The in-situ crystallization ensured successful retention of the shape of the porous $\mathrm{SiO}_{2}$ and $\mathrm{Al}_{2} \mathrm{O}_{3}$ solid raw-materials, resulting in the formation of looser EU-1(S) containing high secondary porosity, consistent with the results of the pore size distribution measurements. The results are in agreement with the results of $\mathrm{N}_{2}$ adsorption/desorption.
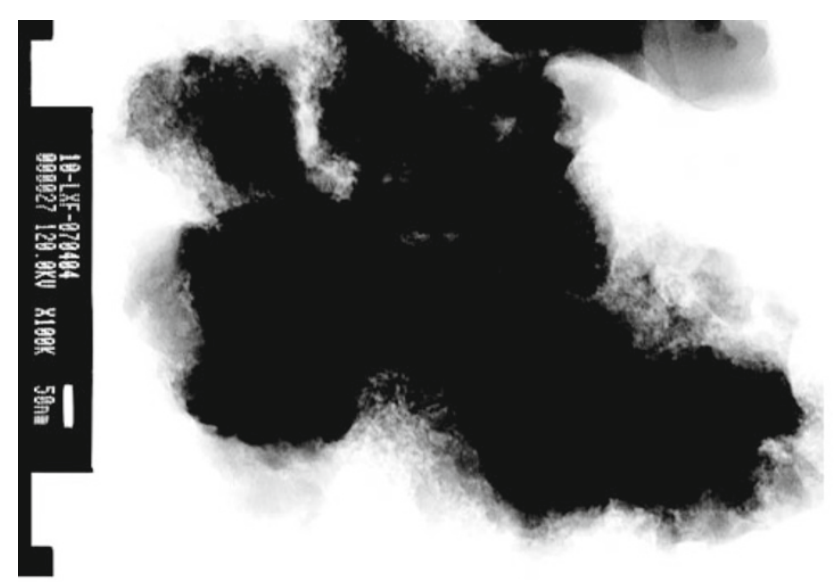

Fig. 6 TEM of EU-1(S) zeolite 
Table 2 Textural properties of EU-1 zeolites

\begin{tabular}{|c|c|c|c|c|c|c|c|}
\hline \multirow{2}{*}{ Sample } & \multirow{2}{*}{$\begin{array}{l}n \mathrm{Si} / n \mathrm{Al} \\
\mathrm{mol} / \mathrm{mol}\end{array}$} & \multicolumn{3}{|c|}{ Surface area, $\mathrm{m}^{2} / \mathrm{g}$} & \multicolumn{3}{|c|}{ Pore volume, $\mathrm{cm}^{3} / \mathrm{g}$} \\
\hline & & BET & External & Micropore & Total & Mesopore & Micropore \\
\hline EU-1(H) & 23.5 & 353 & 24 & 329 & 0.211 & 0.065 & 0.162 \\
\hline EU-1(S) & 24.1 & 356 & 37 & 318 & 0.243 & 0.095 & 0.155 \\
\hline
\end{tabular}

\subsection{Effect of acidity on catalyst performance}

The acidity of EU-1(S) plays a vital role in the catalyst performance in $\mathrm{C}_{8}$ aromatics isomerization. So the acidity of the EU-1(S) after steam treatment at different temperatures was characterized by the Py-IR method and the results are shown in Table 3 and Fig. 7. When the treatment temperature was increased from $300{ }^{\circ} \mathrm{C}$ to $500{ }^{\circ} \mathrm{C}$, the number of the total Brønsted acid sites decreased from 5.8 to 2.0 and the number of the strong Brønsted acid sites decreased from 5.5 to 1.4. The ratio of the strong Brønsted acid sites to the total Brønsted acid sites decreased from $94.8 \%$ to $70 \%$, indicating that steam treatment mainly deactivates the strong Brønsted acid sites. Meanwhile, it may change the acid site distribution, and inhibit the unwanted bimolecular reaction. Further research will be needed for the mechanism study.

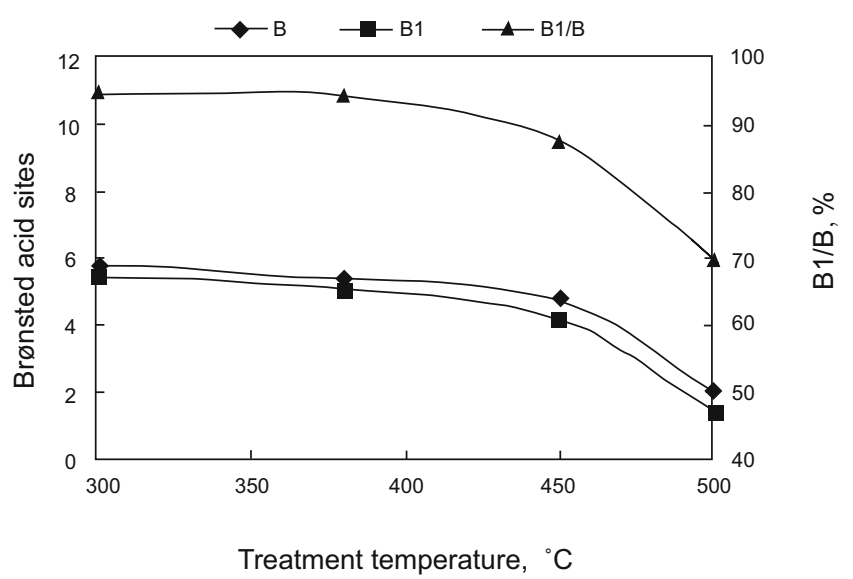

Fig. 7 Relative Brønsted acid sites of HEU-1(S) after steam treatment under different conditions

B: Brønsted acid sites; B1: Strong Brønsted acid sites
The isomerization catalyst was prepared by using steam treated HEU-1(S) zeolite as the acid component. The reaction results over this isomerization catalyst are shown in Fig. 8 . It can be seen that with increasing temperature of steam treatment, the reaction activity parameter (i.e. ethylbenzene conversion rate) $\mathrm{EB}_{\mathrm{C}}$ reduced remarkably from $29.0 \mathrm{wt} \%$ to $22.8 \mathrm{wt} \%$. Meanwhile, another reaction activity parameter (i.e. equilibrium concentration of $\mathrm{PX}) \mathrm{PX} / \Sigma \mathrm{X}$ decreased slightly from $23.2 \mathrm{wt} \%$ to $22.0 \mathrm{wt} \%$. However, the reaction selectivity parameter (i.e. Yield of $\mathrm{C}_{8}$ ) $\mathrm{C}_{8} \mathrm{Y}$ increased from $97.5 \mathrm{wt} \%$ to $98.2 \mathrm{wt} \%$. With increasing temperature of steam treatment from $300{ }^{\circ} \mathrm{C}$ to $500{ }^{\circ} \mathrm{C}$, the strong Brønsted acid sites of the catalyst decrease by $74.6 \%$ (Fig. 7), and the activity of xylene isomerization and ethylbenzene conversion reactions decreased accordingly, while the reaction yields increased (Table 3 and Fig. 8).

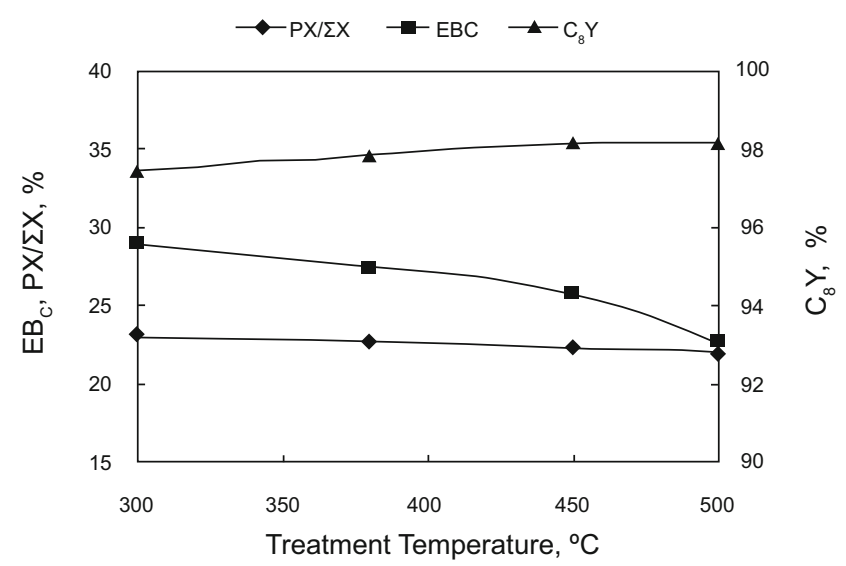

Fig. 8 Reaction performance of EU-1(S) based catalyst after steam treatment at different temperatures

Reaction conditions: $365^{\circ} \mathrm{C}, 0.60 \mathrm{MPa}$, WHSV $=5.0 \mathrm{~h}^{-1}$, $n\left(\mathrm{H}_{2}\right): n($ liquid feedstock $)=3.2$

These results indicated that side reactions such as cracking and disproportion are inhibited, demonstrating that strong Brønsted acid sites are both sites of $\mathrm{C}_{8}$ aromatics isomerization and side reactions such as cracking and disproportion. These results agree with previous research (Fernandes et al, 1998).

Table 3 Reaction performance of EU-1(S) based catalyst after steam treatment at different temperatures

\begin{tabular}{cccc}
\hline \multirow{2}{*}{$\begin{array}{c}\text { Treatment temperatures } \\
{ }^{\circ} \mathrm{C}\end{array}$} & \multicolumn{3}{c}{ Reaction performance, wt\% } \\
\cline { 2 - 4 } & $\begin{array}{c}\text { Equilibrium concentration } \\
\text { of } \mathrm{PX}(\mathrm{PX} / \Sigma \mathrm{XX})\end{array}$ & $\begin{array}{c}\text { Ethylbenzene conversion } \\
\text { rate }\left(\mathrm{EB}_{\mathrm{C}}\right)\end{array}$ & Yield of $\mathrm{C}_{8}\left(\mathrm{C}_{8} \mathrm{Y}\right)$ \\
\hline 300 & 23.2 & 29.0 & 97.5 \\
380 & 22.7 & 27.4 & 97.8 \\
450 & 22.4 & 25.9 & 98.1 \\
500 & 22.0 & 22.8 & 98.2 \\
\hline
\end{tabular}

This investigated ethylbenzene conversion on catalysts prepared with different silica/alumina ratios and different amounts of beta zeolite and obtained the following results: Brønsted acid sites on beta zeolite (not all the Brønsted acids that can be detected by IR-Pyridine method) are the active centers for $\mathrm{C}_{8}$ aromatics isomerization. In our research, we further uncover that the strong Brønsted acid sites on HEU1(S) zeolite are responsible for $\mathrm{C}_{8}$ aromatics isomerization after the steam treatment.

Hence, steam treatment can improve catalytic selectivity which is important for industrial $\mathrm{C}_{8}$ aromatics isomerization, because the total PX yields are improved with more economic 
profits. The loss of catalyst activity due to the steam treatment can be compensated by adjusting process parameters (Gui et al, 2009) with higher selectivity to PX.

\subsection{Effect of metal function on catalyst properties}

Xylene isomerization catalyst is a bifunctional catalyst. The best results of ethylbenzene conversion are obtained when keeping the balance between metal and acidic functions. For zeolites with different acidities, there is suitable range of metal loading amount. For a definite acidity of zeolite, there are many factors affecting metal function such as metal loading amount, metal dispersion, the interaction between the metal and the support and the immobilization method (Liu et al, 2010). This paper investigated the effect of the amount of platinum on the catalytic properties of EU-1(S) zeolite with a hierarchical mesopore structure.

To investigate the effect of $\mathrm{Pt}$ amount on the catalyst properties, the zeolite amount, exchange degree, impregnation method, activation and reduction process were all kept the same. The results are shown in Fig. 9. It can be seen that with Pt content increasing from $0.1 \mathrm{wt} \%$ to $0.4 \mathrm{wt} \%$, the EB conversion increased; When Pt content increased from $0.4 \mathrm{wt} \%$ to $0.5 \mathrm{wt} \%$, the EB conversion decreased slightly. Obviously, it was resulted from the metal function of the catalyst. Under an atmosphere of hydrogen, the activation of hydrocarbons by metal $\mathrm{Pt}$ is a rapid reaction. Furthermore, the hydrogenation of EB is also a quick process, and the products of EB hydrogenation are precursors of $\mathrm{EB}$ conversion to xylene. The higher the metal content, the more numerous the active metal sites, hence more hydrocarbons were activated and hydrogenated.

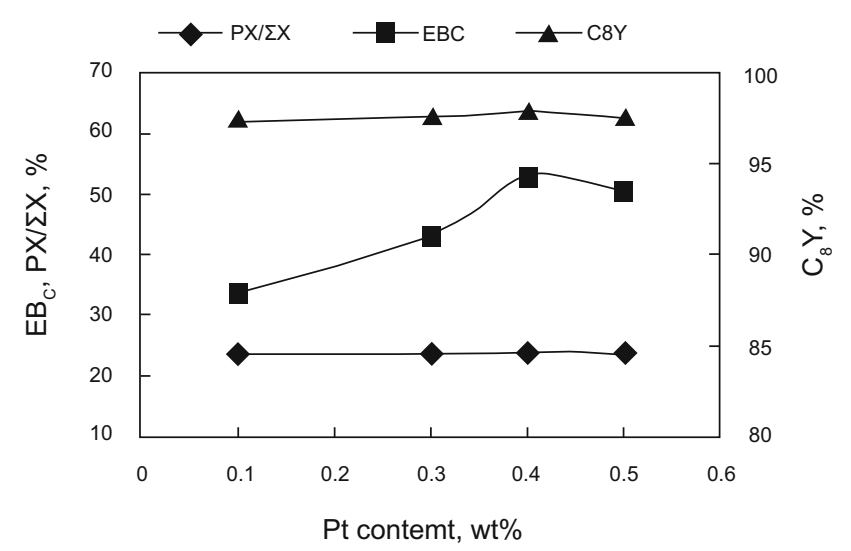

Fig. 9 Catalyst performance at different Pt contents Reaction conditions: $365^{\circ} \mathrm{C}, 0.60 \mathrm{MPa}, \mathrm{WHSV}=5.0 \mathrm{~h}^{-1}$, $n\left(\mathrm{H}_{2}\right): n($ liquid feedstock $)=3.2$

From the aspect of catalyst selectivity, with the Pt content increasing from $0.1 \mathrm{wt} \%$ to $0.4 \mathrm{wt} \%$, the yield of $\mathrm{C}_{8}\left(\mathrm{C}_{8} \mathrm{Y}\right)$ increased and reached to a maximum. However, when $\mathrm{Pt}$ content increased to $0.5 \mathrm{wt} \%$, the $\mathrm{C}_{8} \mathrm{Y}$ decreased instead (Table 4). It means that, for a specific acid function of EU1(S) zeolite, Pt content of $0.4 \mathrm{wt} \%$ is the optimum amount. From the aspect of side reactions, with increasing Pt content, both the disproportionation reaction and the transalkylation reaction decreased, indicating that the Pt loading can inhibit side reactions for this catalyst. The reason might be that when the Pt content increased, most of $\mathrm{Pt}$ was loaded on $\mathrm{Al}_{2} \mathrm{O}_{3}$, but some of metal $\mathrm{Pt}$ was absorbed on zeolite and deposited in the pores or at the pore mouths, which can modify the pore size of zeolite, and reduce the diffusion of large molecules. For the dealkylation reaction, there was no significant change with increasing Pt content, because the strong acid sites which responsible for dealkylation remained unchanged. For the cracking side reactions, there was a slight increase with increasing Pt content (Table 4). It is because that with increasing Pt content, the strong acid sites did not decrease, even though the dispersion of Pt decreases which will affect its dehydrogenation function. Furthermore, the increment of $\mathrm{Pt}$ in the pores of zeolite can promote the probability of secondary reactions of $\mathrm{C}_{8}{ }^{\mathrm{N}+\mathrm{P}}$. On the other hand, with the $\mathrm{Pt}$ content rising, the reaction characteristic above confirmed the existence of a unique structure with pore size gradient distribution of mesopores formed by the nanoclusters of micro crystal particles.

Table 4 Catalyst performance at different Pt contents

\begin{tabular}{cccc}
\hline \multirow{2}{*}{$\begin{array}{c}\text { Pt Contents } \\
\text { wt\% }\end{array}$} & $\begin{array}{c}\text { Reaction performance, wt\% } \\
\text { concentration of } \\
\text { PX }\left(\mathrm{PX} / \sum \mathrm{X}\right)\end{array}$ & $\begin{array}{c}\text { Ethylbenzene conversion } \\
\text { rate }\left(\mathrm{EB}_{\mathrm{C}}\right)\end{array}$ & $\begin{array}{c}\text { Yield of } \mathrm{C}_{8} \\
\left(\mathrm{C}_{8} \mathrm{Y}\right)\end{array}$ \\
\hline 0.1 & 23.6 & 33.5 & 97.4 \\
0.3 & 23.6 & 43.2 & 97.6 \\
0.4 & 23.8 & 52.9 & 97.9 \\
0.5 & 23.6 & 50.6 & 97.6 \\
\hline
\end{tabular}

\subsection{Comparison of catalytic performance with MOR and/or EU-1(H) contained catalyst}

Three catalysts, MOR containing industrial catalyst, catalyst containing EU-1(H) prepared by the conventional hydrothermal method, and the catalyst containing EU$1(\mathrm{~S})$ synthesized by the new quasi-solid state approach, were evaluated under their optimal operation conditions respectively with $85.0 \mathrm{wt} \%$ meta-xylene and $15.0 \mathrm{wt} \%$ ethylbenzene as the feedstock. The results are listed in Table 5.

The results showed that both the activity (i.e. PX/ $/ \mathrm{X}$ and $\mathrm{EB}_{\mathrm{C}}$ ) and selectivity (i.e. $\mathrm{C}_{8} \mathrm{Y}$ ) of the catalyst with EU-1 catalyst are higher than the catalyst containing MOR. That means with the profitable adjustment of catalyst acidity, the high activity of EU-1 containing catalysts can be achieved, and the selectivity can be enhanced simultaneously. Their integrated performance is better than the MOR catalyst. Compared with the EU-1(H) catalyst, the EU-1(S) catalyst shows high EB conversion, $\mathrm{C}_{8}$ aromatics yield and paraxylene selectivity.

From the results of catalyst characterization, the EU$1(\mathrm{~S})$ containing catalyst shows good performance because EU-1-(S) zeolite has a large quantity of mesopores. Under similar situation of pore volume and acidity, the mesopores of the zeolites are favorable to the diffusion of para-xylene in the catalyst. Therefore, EU-1(S) catalyst which has more mesopores shows higher EB conversion than other two catalysts. Since the $\mathrm{C}_{8}$ aromatics isomerization is a 
typical diffusion-limited reaction, the unique pore structure of EU-1(S) with abundant mesopores are favorable to the accessibility of reactants and the diffusion of PX product, thus leading to the increment of PX yields.

Table 5 Evaluation results

\begin{tabular}{cccc}
\hline & \multicolumn{3}{c}{ Reaction performance, wt\% } \\
\cline { 2 - 4 } Catalyst & $\begin{array}{c}\text { Equilibrium } \\
\text { concentration of } \\
\text { PX }(\mathrm{PX} / \Sigma \mathrm{X})\end{array}$ & $\begin{array}{c}\text { Ethylbenzene conversion } \\
\text { rate }\left(\mathrm{EB}_{\mathrm{C}}\right)\end{array}$ & $\begin{array}{c}\text { Yield of } \mathrm{C}_{8} \\
\left(\mathrm{C}_{8} \mathrm{Y}\right)\end{array}$ \\
\hline $\begin{array}{c}\text { Catalyst with } \\
\text { EU-1(S) }\end{array}$ & 24.4 & 39.3 & 99.0 \\
$\begin{array}{c}\text { Catalyst with } \\
\text { EU-1(H) }\end{array}$ & 23.9 & 34.5 & 98.4 \\
$\begin{array}{c}\text { Catalyst with } \\
\text { MOR }^{2)}\end{array}$ & 23.1 & 28.6 & 97.8 \\
\hline
\end{tabular}

Operation conditions:

1) $379^{\circ} \mathrm{C}, 0.72 \mathrm{MPa}$, WHSV $=5.0 \mathrm{~h}^{-1}, n\left(\mathrm{H}_{2}\right): n($ liquid feed $)=3.7$

2) $377^{\circ} \mathrm{C}, 0.73 \mathrm{MPa}$, WHSV $=3.8 \mathrm{~h}^{-1}, n\left(\mathrm{H}_{2}\right): n($ liquid feed $)=4.3$

\section{Conclusions}

In this study, a new high performance $\mathrm{C}_{8}$ aromatics isomerization catalyst was developed based on EU-1(S) zeolite which was synthesized via a quasi-solid state approach. The operation parameters and the modification by steam treating to enhance its catalytic performance were carefully studied.

The performance of isomerization catalyst was determined by its acidic function and metal function. By using the steam treatment, it was shown that some strong Brønsted acid sites existed in EU-1 zeolite were not only the active sites for isomerization reaction but also forthe side reactions like cracking and disproportionation. The selectivity of the catalyst was then enhanced by passivating part of the strong Brønsted acid sites. The optimized steam treating temperature was 450 $500{ }^{\circ} \mathrm{C}$

Normally, the conversion of EB occurs on both the acid component and metal component simultaneously. It was also the same for our EU-1 zeolite synthesized by the quasi-solid state approach. If the metal content was too high, the EB conversion and the reaction selectivity would decrease. In this study, we found that the preferable Pt content was 0.3-0.4 $\mathrm{wt} \%$ for EU-1(S) zeolite.

Compared with the EU-1 zeolite prepared by the conventional hydrothermal method, the EU-1 zeolite synthesized by quasi-solid state approach has more abundant mesopores. Therefore, it has better diffusion performance and shows higher EB conversion and para-xylene selectivity in the isomerization process. In total, the catalyst with EU-1(S) showed a better isomerization performance, which is due to the structural features from quasi-solid state conversion and suitable acidity by steam treatment.

\section{Acknowledgements}

This work was financially supported by the National Natural Science Foundation of China (No. 20973123) and the National Basic Research Program of China (Grant No.

\section{CB215002).}

\section{References}

Arnold A, Hunger M andWeitkamp J. Dry-gel synthesis of zeolites [Al] EU-1 and [Ga]EU-1. Microporous and Mesoporous Materials. 2004. 67(2-3): 205-213

Briscoe N A, Johnson D W, Shannon M D, et al. The framework topology of zeolite EU-1. Zeolites. 1988. 8(1): 74-76

Casci J L, Lowe B M and Whittam T V. Zeolite EU-1 and a method of making zeolite EU-1. US patent. USP4537754. 1981

Dou T, Li X F, Xu J Y, et al. Method of preparing molecular sieve with EUO structure from silicon aluminum oxide powder. CN100540471. 2009 (in Chinese)

Fernandes L D, Monteiro J L F, Sousa-Aguiar E F, et al. Ethylbenzene hydroisomerization over bifunctional zeolite based catalysts: The influence of framework and extraframework composition and zeolite structure. Journal of Catalysis. 1998. 177(2): 363-377

Gao Z. Catalysis and separation technology of zeolite. Beijing: China Petrochemical Press. 1999. 254-256 (in Chinese)

Gnep N S, Martin de Armando M L, Marcilly C, et al. Toluene disproportionation and coke formation on mordenites effect of catalyst modifications and of operating conditions. In: Delmon B, Froment G F, eds. Studies in Surface Science and Catalysis. Volume 6: Elsevier. 1980. 79-89

Gui P, Zhang C T, Fu X G and Dou T. A novel $\mathrm{C}_{8}$ aromatics isomerization catalyst II. Study on Running Conditions. 2009. 38(5): 493-496 (in Chinese)

Liu W Q, Shang T M, Zhou Q F, et al. Study on the physicochemical and isomerization property of $\mathrm{Pt} / \mathrm{SAPO}-11$ catalysts promoted by metallic additive. Journal of Fuel Chemistry and Technology. 2010. 38(2): 212-217 (in Chinese)

Mi D. Market analysis of xylene in 2007 worldwide. Chemical Industry. 2008. 26(7): 52-56 (in Chinese)

Moreau F, Moreau P, Gnep N S, et al. Ethylbenzene isomerization over bifunctional platinum alumina-EUO catalysts: Location of the active sites. Microporous and Mesoporous Materials. 2006. 90(1-3): 327338

Shi L. PetroChina's novel $\mathrm{C}_{8}$ aromatics isomerization catalyst has realized industrial application. Technology \& Economics in Petrochemicals. 2009. 25(6): 6 (in Chinese)

Souverijns W, Rombouts L, Martens J A and Jacobs P A. Molecular shape selectivity of EUO zeolites. Microporous Materials. 1995. 4(23): $123-130$

Tukur N M and Al-Khattaf S. Comparison studies of xylene isomerization and disproportionation reactions between SSZ33, TNU-9, mordenite and ZSM-5 zeolite catalysts. Chemical Engineering Journal. 2011. (166): 348-357

Wang J W, Gui S X and Jing Z H. Progress with xylene isomerization catalysts. Chemical Industry and Engineering Progress. 2004. 23(3): 244-247 (in Chinese)

Xu Q H, Gong Y J, Xu W J, et al. Synthesis of high-silica EU-1 zeolite in the presence of hexamethonium ions: A seeded approach for inhibiting ZSM-48. Journal of Colloid and Interface Science. 2011. 358(1): 252-260

Yang J and Shi D P. Commercial application of SKI-400 catalyst for $\mathrm{C}_{8}$ aromatic isomerization. Petroleum Refinery Engineering. 2005. 35(4): 30-33 (in Chinese)

Yeong Y F, Abdullah A Z, Ahmad A L, et al. Synthesis, characterization and reactive separation activity of acid-functionalized silicalite- 1 catalytic membrane in $\mathrm{m}$-xylene isomerization. Journal of Membrane Science. 2010. (360): 109-122 